\title{
Sevoflurane anesthesia during pregnancy in mice induces hearing impairment in the offspring
}

This article was published in the following Dove Press journal:

Drug Design, Development and Therapy

\author{
Xia Shen ${ }^{1, *}$ \\ Yanan Xiaol,* \\ Wen $\mathrm{Li}^{2}$ \\ Kaizheng Chen' \\ Huiqian $\mathrm{Yu}^{3}$ \\ 'Department of Anesthesiology, \\ Shanghai Eye, Ear, Nose, and Throat \\ Hospital, Fudan University, Shanghai \\ 20003I, People's Republic of China; \\ ${ }^{2}$ Research Center, Shanghai Eye, Ear, \\ Nose, and Throat Hospital, Fudan \\ University, Shanghai 20003I, People's \\ Republic of China; ${ }^{3}$ Department of \\ Otorhinolaryngology, Shanghai Eye, \\ Ear, Nose, and Throat Hospital, Fudan \\ University, Shanghai 20003I, People's \\ Republic of China \\ *These authors contributed equally \\ to this work
}

Introduction: Exposure to gamma-aminobutyric acid-mimetics and N-methyl-D-aspartatereceptor antagonists during pregnancy may lead to hearing loss and long-term behavioral abnormalities in the offspring. The purpose of this study was to explore the association between prenatal exposure to sevoflurane (SEV) anesthesia and hearing impairment in mice.

Materials and methods: On gestational day 15, pregnant Kunming mice were exposed for 2 hours to $2.5 \%$ SEV plus $100 \%$ oxygen (anesthesia group) or $100 \%$ oxygen alone (control group).

Results: During auditory brainstem response testing on P30, offspring of the anesthesia group mice exhibited higher hearing thresholds at $8,16,24$, and $32 \mathrm{kHz}$; longer peak latency of wave II at all four frequencies; and longer interpeak latencies from waves II to $\mathrm{V}$ at 16, 24, and $32 \mathrm{kHz}$, compared to the control offspring. Caspase-3, iNOS, and COX-2 activation occurred in the fetal cochlea of the anesthesia group. Mitochondrial swelling was observed in the anesthesia group offspring at P1 and P15.

Conclusion: Our results suggest that SEV exposure during pregnancy may cause detrimental effects on the developing auditory system.

Keywords: sevoflurane, auditory brainstem response, apoptosis, cochlea, pregnant mice

\section{Introduction}

Cognition and sensation/perception are interrelated functions, ${ }^{1}$ and hearing impairment can be associated with cognitive deficits. ${ }^{2,3}$ In older adults, hearing loss has been associated with an increased likelihood of future cognitive impairment, suggesting that impaired hearing may have a causal role in the declining cognition. ${ }^{4}$ In children, hearing impairment at a critical period during hearing development (within the first 2 or 3 years) may lead to permanent deficits in language, speech, and even intellect. ${ }^{5,6}$

The developing auditory system is susceptible to toxic agents. ${ }^{7-9}$ Ethanol is an example of one of these agents. It has both gamma aminobutyric acid (GABA)mimetic and N-methyl-D-aspartate (NMDA)-antagonist activity. Ethanol exposure during pregnancy has been associated with not only neurotoxicity in the fetus but also behavioral abnormalities ${ }^{10,11}$ and detrimental effects on the developing auditory system in the offspring. ${ }^{12-14}$

Fetal exposure to valproic acid, ethanol, and the anesthetic isoflurane can lead to behavioral abnormalities during adulthood. ${ }^{15,16}$ Furthermore. Wilder et al reported that children with more than one exposure to anesthesia when they were young had an increased likelihood of subsequently developing learning disabilities. ${ }^{17}$ However, supplementary data provided by these authors showed that up to $16.7 \%$ of the children had both otitis and learning and memory disabilities before the age of 4 years. It is quite possible that many of the children with otitis had at least some degree of hearing 
impairment, although it is not known to what extent the hearing impairment contributed to the cognitive dysfunction.

General anesthetic agents are either GABA-mimetic or NMDA-receptor antagonist drugs. Whether general anesthetics have ototoxic effects similar to those observed with ethanol is currently unknown. A recent study showed that sevoflurane (SEV) exposure in pregnant mice was associated with subsequent memory and learning impairment in the offspring. ${ }^{18}$ The current study was thus performed to determine whether the use of $2.5 \% \mathrm{SEV}$ anesthesia in pregnant mice produced detrimental effects in the developing auditory system of either fetal mice or offspring after birth.

\section{Materials and methods}

\section{Animals}

All procedures involving study animals were approved by the Animal Care and Use Committee of Fudan University and conducted in accordance with the National Institutes of Health Guide for the Care and Use of Laboratory Animals. Vigorous attempts were made to limit the quantity of animals used and to preclude any suffering. Three-month-old Kunming female and male mice were mated. When pregnant mice were identified, they were moved to individual housing. The offspring were weaned 21 days after they were born. All mice were maintained in a temperature-controlled room (ranging from $22^{\circ} \mathrm{C}$ to $23^{\circ} \mathrm{C}$ ) and subjected to a 12 -hour light/dark cycle, with the lights being turned on at 7:00 am each day. Routine mouse chow and water were accessible on an ad libitum basis.

\section{Anesthesia}

On the 15th gestational day (G15), the pregnant mice were assigned at random to one of two groups: anesthesia group or control (no-anesthesia) group. The anesthesia group mice were placed in an anesthetizing chamber and exposed for 2 hours to $2.5 \%$ SEV and $100 \%$ oxygen. The control group mice were placed in a similar chamber and were exposed for 2 hours to $100 \%$ oxygen alone (at identical flow rates). The mice breathed spontaneously throughout the exposure period. SEV concentrations were continuously measured by a calibrated Vamos (Dräger, Lübeck, Germany) side-stream gas analyzer. The chamber temperature was regulated to keep the rectal temperature of each mouse at $37^{\circ} \mathrm{C} \pm 0.5^{\circ} \mathrm{C}$. During the 2-hour exposure period, samples of venous blood were obtained from the inner canthus of each animal $(n=5$ in each group). At the end of the anesthetic exposure, the mice were placed in a 100\% oxygen chamber until 20 minutes after their righting reflex returned.

\section{Experimental design}

Cochlear tissues were harvested from fetal mice 2 hours after SEV exposure ( $n=8$ in control group, $n=10$ in SEV group), to be used for Western blot analysis. Cochlear tissues were harvested from offspring mice after birth ( $n=6$ per group) on postnatal day (P)1, P15, and $\mathrm{P} 30$ ( $\mathrm{P} 0=$ day of birth), to be used for transmission electron microscopy (TEM). Auditory brainstem response (ABR) testing ( $n=8$ in control group, $\mathrm{n}=13$ in SEV group) was performed on P30. An assessor blinded to the groups measured the outcomes.

\section{Auditory brainstem response testing}

The ABR test was used to examine the hearing threshold of the mice. Before the test, each animal was confirmed to have normal external auditory canals and tympanic membranes and no tympanitis. Each mouse was anesthetized with $100 \mathrm{mg} / \mathrm{kg}$ ketamine and $25 \mathrm{mg} / \mathrm{kg}$ xylazine $^{19}$ and placed on a thermostatic heating pad to keep the body temperature at $37^{\circ} \mathrm{C}$. ABR tests were conducted in a soundproof anechoic chamber. The response was recorded by needle electrodes positioned subcutaneously at the right mastoid prominence, vertex, and tip of the nose. The speaker was positioned $5 \mathrm{~cm}$ away from each mouse. The neuronal activity was amplified $(100,000 \mathrm{U})$, filtered $(0.3 \mathrm{kHz}-3.0$ $\mathrm{kHz}$ ), and then digitized with an analog-to-digital (A/D) converter (AD3; Tucker-Davis Technologies, Alachua, FL, USA). Tone burst stimuli with a duration of 5 milliseconds and rise-fall time of 0.5 milliseconds were generated. The response was recorded as the mean response to 1,000 repetitive stimuli delivered at each of four frequencies: 8, 16, 24, and $32 \mathrm{kHz}$. At each frequency, the hearing threshold was determined by decreasing the intensity of the stimulus from a suprathreshold level. Starting at $100 \mathrm{~dB}$ sound pressure level (SPL), the intensity was decreased in increments of $10 \mathrm{~dB}$ SPL until the intensity was $20 \mathrm{~dB}$ SPL. At a level lower than this, the intensity was reduced in increments of $5 \mathrm{~dB}$ until a recognizable wave response (two or more consistent characteristic waveforms) was noted.

\section{Cochlear tissue harvesting and protein quantification}

Two hours after the pregnant mice were exposed to SEV anesthesia (or the $100 \%$ oxygen-only control conditions), a caesarean section was performed to deliver the fetus and harvest the cochlear tissues for Western blot analysis. On P1, P15, and P30, offspring mice were euthanized by decapitation, and their cochlea tissues were harvested for subsequent analysis by TEM. 
The cochlear tissues used for Western blot testing were homogenized on ice using an immunoprecipitation buffer (10 mM Tris- $\mathrm{HCl} \mathrm{pH} 7.4,2 \mathrm{mM}$ ethylenediaminetetraacetic acid, $0.5 \%$ Nonidet P-40, $150 \mathrm{nM} \mathrm{NaCl}$ ), as well as protease inhibitors $(1 \mu \mathrm{g} / \mathrm{mL}$ leupeptin, $1 \mu \mathrm{g} / \mathrm{mL}$ aprotinin, and $1 \mu \mathrm{g} / \mathrm{mL}$ pepstatin A). ${ }^{20}$ The lysates were centrifuged for 15 minutes at $12,000 \mathrm{rpm}$, and the total protein was quantified with a bicinchoninic acid protein assay kit (Pierce Technology Co., Iselin, NJ, USA).

\section{Western blot analysis}

The total protein extracted from four cochleas was combined to provide a sufficient amount of protein for the Western blot analysis. Western blot tests were conducted as in prior studies. ${ }^{20}$ Caspase-3 antibody (1:1,000, CY3457; Abways Technology, Beijing, People's Republic of China), Bcl-2 (1:1,000, ab32124; Abcam, Cambridge, MA, USA), COX-2 (1:1,000, ab15191; Abcam), iNOS (1:1,000, ab15323; Abcam), glyceraldehyde 3-phosphate dehydrogenase (GAPDH) antibody $(1: 1,000$, rabbit polyclonal; Cell Signaling Technology, Beverly, MA, USA), and $\beta$-actin $(1: 1,000, a b 8226$; Abcam) were the primary antibodies. The membranes were incubated in a blocking buffer containing horseradish peroxidase-conjugated secondary antibody (1:5,000; SuperSignal West, Pierce, Rockford, IL, USA). Semiquantification of the bands was performed with ImageJ software (NIH Image, Bethesda, MD, USA). Expression of GAPDH was used as a control to account for differences in the amount of loaded total protein; the semiquantitative values were normalized to the GAPDH levels.

\section{Transmission electron microscopy}

On P1, P15, and P30, two offspring mice of each dam were chosen at random for exploratory TEM histologic examination. The organ of Corti was dissected under a dissecting microscope, and then submerged in $0.18 \mathrm{M}$ sucrose in 0.1 PBS rinse solution. Three washes were performed. The tissues were subsequently placed in $1 \%$ osmium tetroxide for 2 hours. This was followed by dehydration in increasing concentrations of alcohol (from 50\% to 100\%) and then embedding in Epon618. The samples were viewed by contrast phase microscopy, during which they were embedded in the encasement in a standardized orientation. The embedded samples were then dried overnight in an oven to achieve solidification. The next day, they were viewed with an anatomic microscope. An ultramicrotome (Reichert Ultracut E; Leica AG, Vienna, Austria) was used to generate semithin $(0.7 \mu \mathrm{m})$ sections. After drying at $70^{\circ} \mathrm{C}-80^{\circ} \mathrm{C}$, the samples were stained with $1 \%$ toluidine blue, and then visualized to assess cochlear morphology. Ultrathin $(70 \mathrm{~nm})$ sections were created using an ultramicrotome (Leica AG, Reichert Division). These samples underwent staining with leadcitrate and uracyl-acetate, followed by imaging with a Philips CM-120 TEM (Philips, Amsterdam, Holland).

\section{Statistical analysis}

In our pilot study, we found that the ABR threshold in the control group was $28.1 \pm 5.1 \mathrm{~dB}$ at $8 \mathrm{kHz}$ during ABR test. Based on an estimate of $25 \%$ increment in ABR thresholds, we calculated that at least 8 mice in each group were required to give the study a statistical power of $80 \%$ at a $5 \%$ level of significance.

The data were shown as mean \pm SD. Data distribution was tested with the Shapiro-Wilk test and was found to be normal. Student's $t$-test was used to compare blood gas values between groups. Interaction between frequency and group factors in a two-way analysis of variance (ANOVA) with repeated measurements was used to analyze differences of hearing function (ie, ABR thresholds, peak latency of wave II, and interpeak latency of wave II to V) between control group and SEV group. The post hoc Bonferroni test was used to compare differences between the two groups at different frequencies. $P$-values of 0.05 were considered significant. SAS software version 9.2 (SAS Institute Inc., Cary, NC, USA) was used to analyze the data.

\section{Results}

Venous blood gas values of the pregnant mice during anesthesia (or 100\% oxygen-only control conditions) were similar for the two groups (Table 1). The offspring mice were delivered at $\mathrm{G} 21$. No spontaneous abortions, premature deliveries, fetal demise, intrauterine growth restriction, or congenital defects occurred (data not shown).

ABR testing showed that hearing thresholds at different frequencies were elevated in the anesthesia group compared to the control group. ANOVA did not show a significant difference in hearing thresholds over the four frequencies between

Table I Blood gas values in pregnant Kunming mice during control conditions and sevoflurane anesthesia, mean (SD)

\begin{tabular}{lll}
\hline Blood gas & Control & Sevoflurane \\
\hline $\mathrm{pH}$ & $7.34(0.04)$ & $7.31(0.04)$ \\
$\mathrm{PvO}_{2}(\mathrm{mmHg})$ & $133(10)$ & $135(9)$ \\
$\mathrm{PvCO}_{2}(\mathrm{mmHg})$ & $41.5(3.5)$ & $40.8(3.3)$ \\
\hline
\end{tabular}

Abbreviations: $\mathrm{PvCO}_{2}$, mixed venous carbon dioxide tension; $\mathrm{PvO}_{2}$, mixed venous oxygen tension. 
A
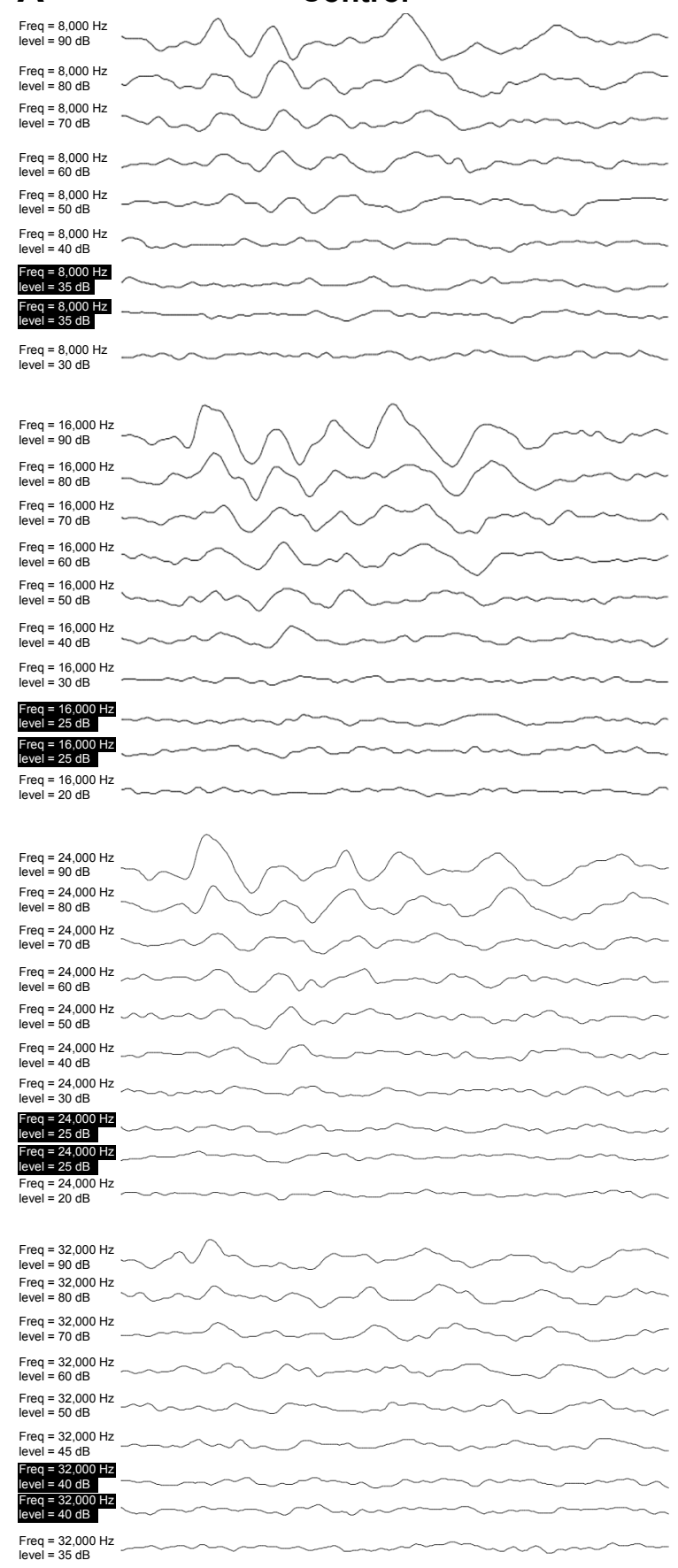
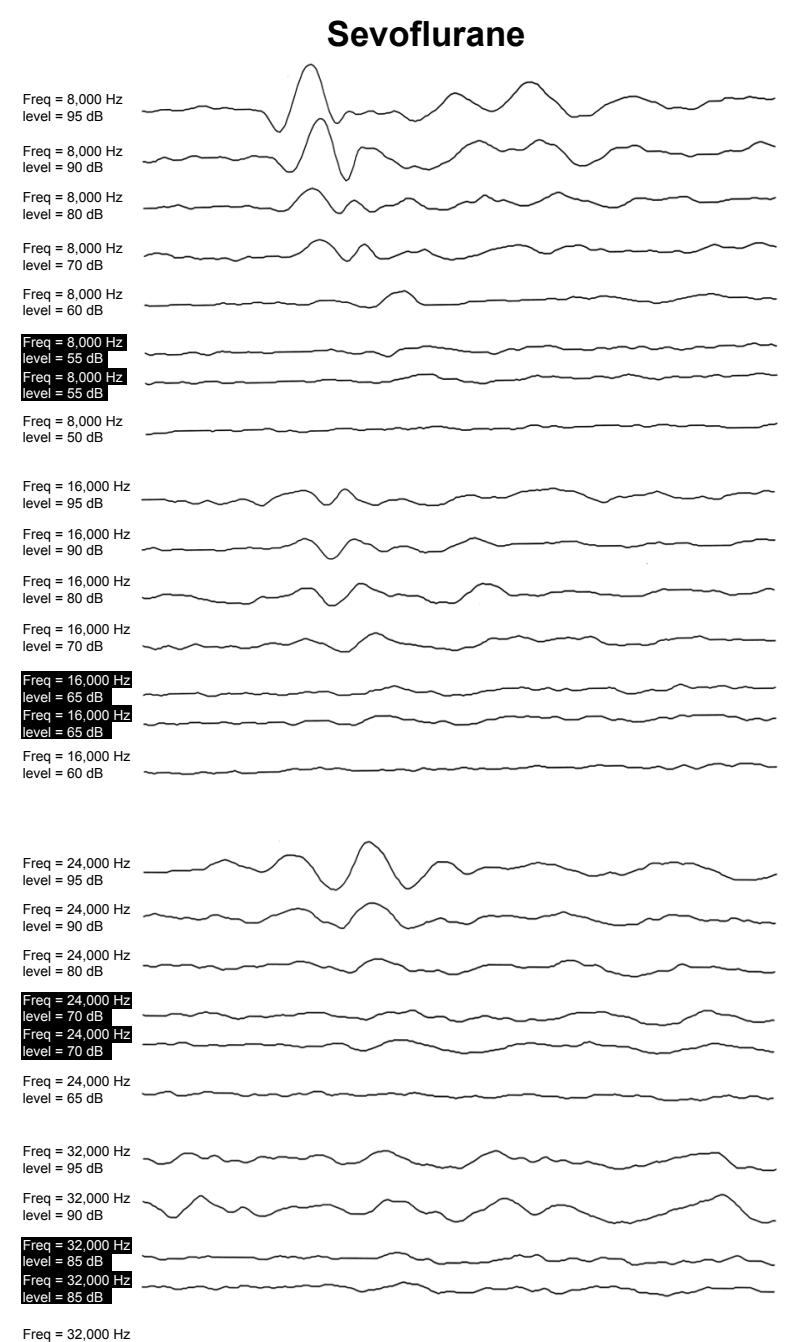

Freq $=32,000 \mathrm{~Hz}$
level $=80 \mathrm{~dB}$

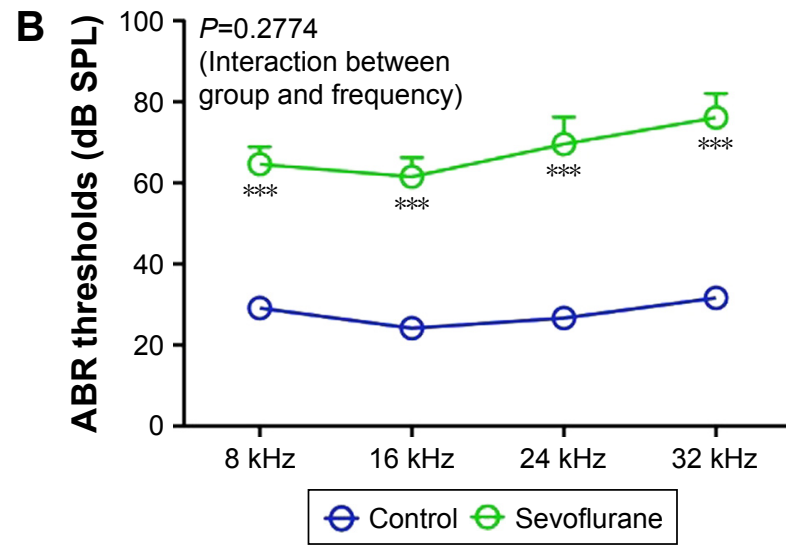

Figure I Sevoflurane anesthesia in pregnant mice induced hearing impairment in offspring mice.

Notes: Illustration of ABR waves in the offspring of the sevoflurane group mice and control group mice (A). Repeated measures analysis of variance did not show a significant difference in hearing threshold over the four frequencies between the sevoflurane group and the control group. However, post hoc Bonferroni tests demonstrated that hearing thresholds were significantly higher in the sevoflurane group than in the control group at $8,16,24$, and $32 \mathrm{kHz}(\mathbf{B})$. $* * * P<0.000 \mathrm{I}$. Abbreviations: ABR, auditory brainstem response; Freq, frequency; SPL, sound pressure level. 
the anesthesia group and the control group $(P=0.2774)$ (Figure 1). However, post hoc Bonferroni tests demonstrated that the SEV group mice had higher thresholds than the control mice at each of the four frequencies $(8,16,24$, and $32 \mathrm{kHz})$.

We calculated the peak latency of wave II and the interpeak latency from wave II to wave $\mathrm{V}$ at a stimulus of $8 \mathrm{kHz}$ and $90 \mathrm{~dB}$ SPL (Figure 2A). ANOVA revealed no difference in latency of wave II over the four frequencies between the anesthesia and control groups $(P=0.1704)$ but post hoc Bonferroni tests showed that the wave II latency was significantly longer in the anesthesia group than in the control group at each of the four frequencies (Figure 2B). Likewise, ANOVA showed no difference in interpeak latency from wave II to wave $\mathrm{V}$ over the four frequencies between groups $(P=0.5963)$; however, post hoc Bonferroni tests indicated that the wave II to wave $\mathrm{V}$ interpeak latency was significantly longer in the anesthesia group than in the control group at 16, 24, and $32 \mathrm{kHz}$ (Figure 2C).
SEV anesthesia for 2 hours in pregnant mice at G15 induced activation of caspase- 3 and Bcl-2 in fetal mice cochlear tissues, as shown by Western blot testing. Semiquantification of the Western blot results revealed that cochlear tissue caspase-3 levels were higher in fetal mice whose mothers were given anesthesia than in fetal mice whose mothers were not exposed to an anesthesia (Figure 3A and B). Cochlear tissue Bcl-2 levels were also higher in SEV group (Figure 3C and D).

SEV anesthesia for 2 hours in pregnant mice at G15 also induced swollen mitochondria in the cochlear neurons and hair cells of offspring mice (Figure 4). On P1, the quantity of swollen mitochondria in the cochlear hair cells and neurons was substantially greater in the anesthesia group than in the control group. The swollen mitochondrial mass remained greater in the anesthesia group on P15, but differences between the two groups were no longer present on $\mathrm{P} 30$.

A
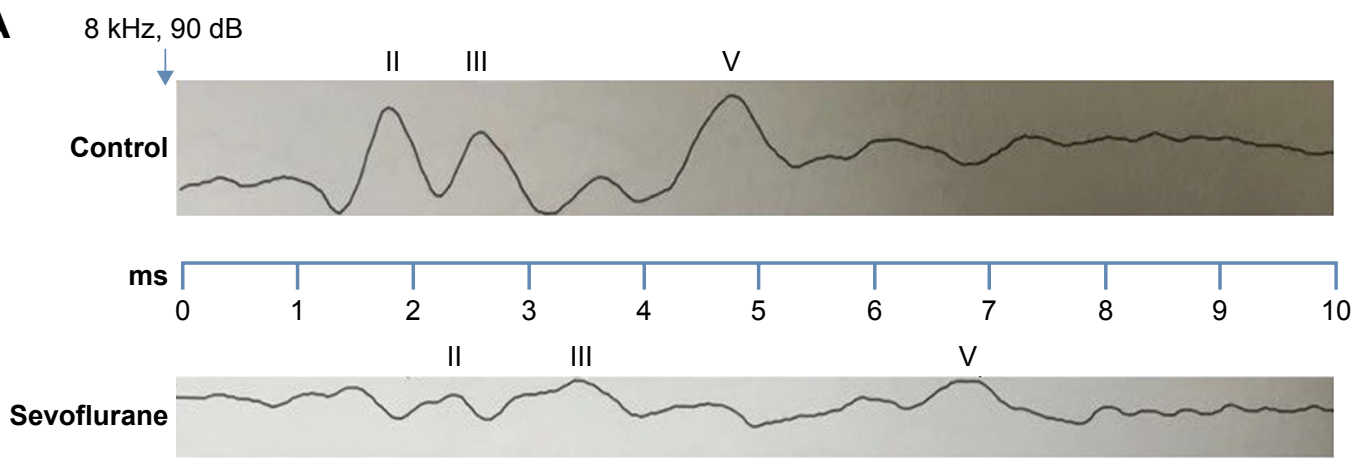

B

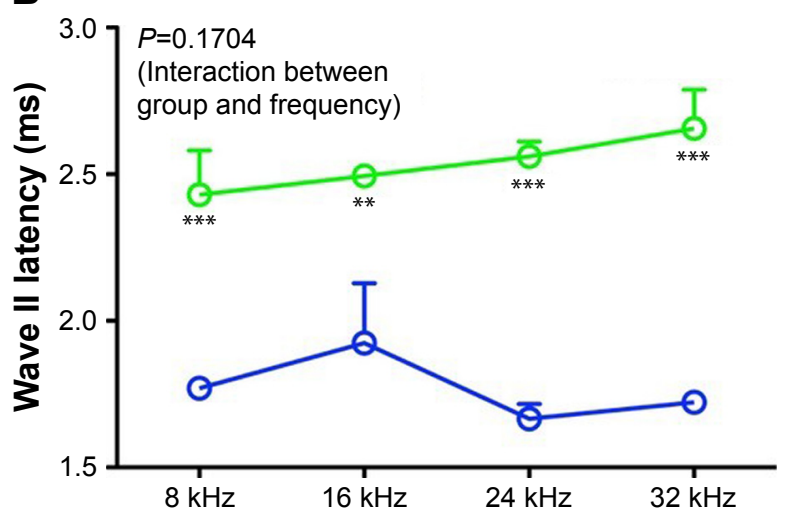

C

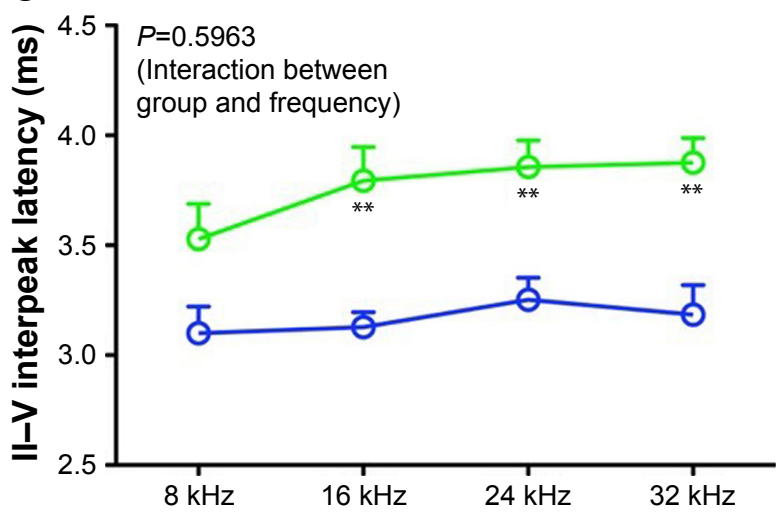

\section{$\ominus$ Control $\ominus$ Sevoflurane}

Figure 2 Sevoflurane anesthesia in pregnant mice induced prolongation of the peak latency and interpeak latency during ABR testing in offspring mice.

Notes: Illustration of ABR waves triggered by an $8 \mathrm{kHz}, 90 \mathrm{~dB}$ sound pressure level stimulus (A). Repeated measures analysis of variance did not show a significant difference in the peak latency of wave II over the four frequencies between the sevoflurane group and the control group. Post hoc Bonferroni tests showed significantly longer peak latency of wave II in the sevoflurane group than in the control group at each of the four frequencies (B). Sevoflurane exposure in pregnant mice also caused a significantly prolonged interpeak (wave II to wave V) latency in the offspring at 16,24, and $32 \mathrm{kHz}(\mathbf{C})$ ) $* * P<0.01$, $* * * P<0.000 \mathrm{I}$.

Abbreviation: $A B R$, auditory brainstem response. 
A

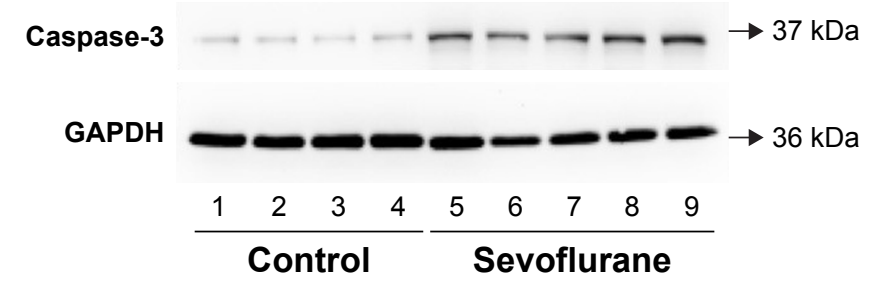

C

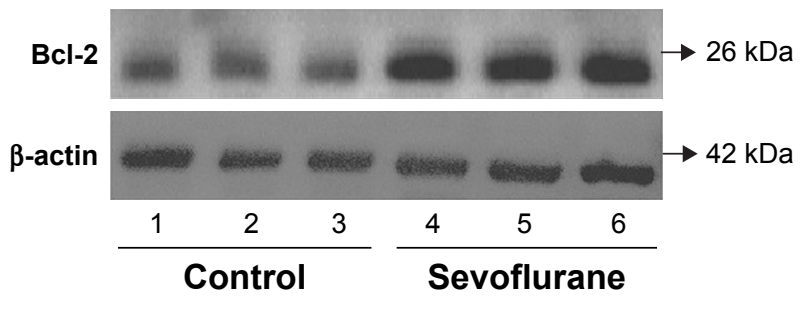

B
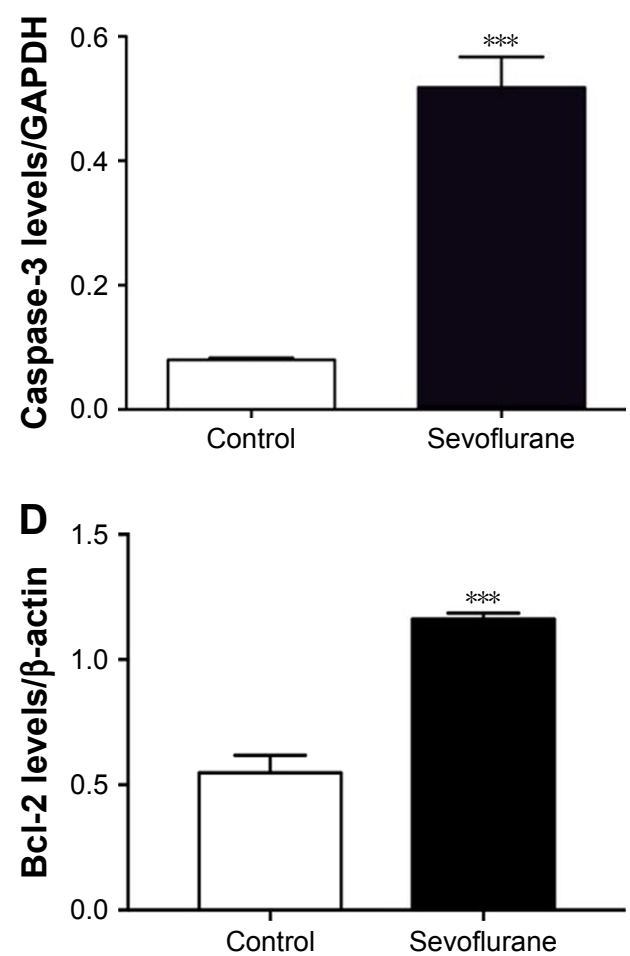

Figure 3 Anesthesia with $2.5 \%$ sevoflurane for 2 hours in pregnant mice on the 15 th day of gestation induced caspase-3 activation in the cochlear tissues of fetal mice. Notes: Representative Western blot images of caspase-3 and glyceraldehyde 3-phosphate dehydrogenase (GAPDH) in fetal tissue samples from the sevoflurane and control groups (A). Semiquantification of the Western blot showed that compared with the control conditions, sevoflurane anesthesia was associated with greater quantities of caspase-3 in fetal mice cochlear tissues (B). Expression of Bcl-2 in fetal cochlear tissues was higher in the sevoflurane group (C and D). $* * * P<0.000$ I.

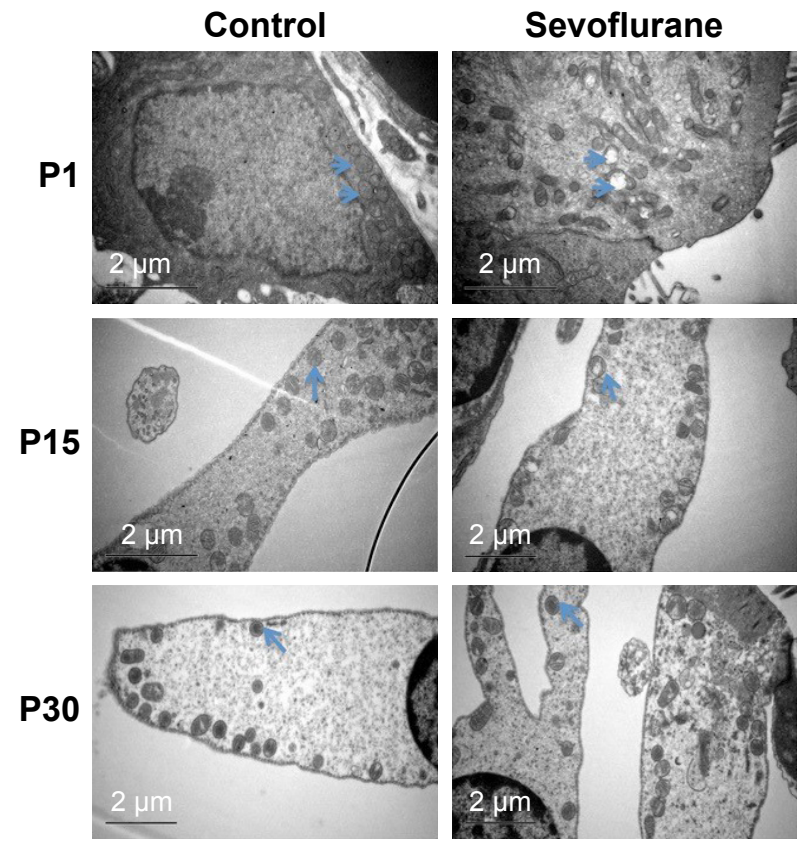

Hair cell
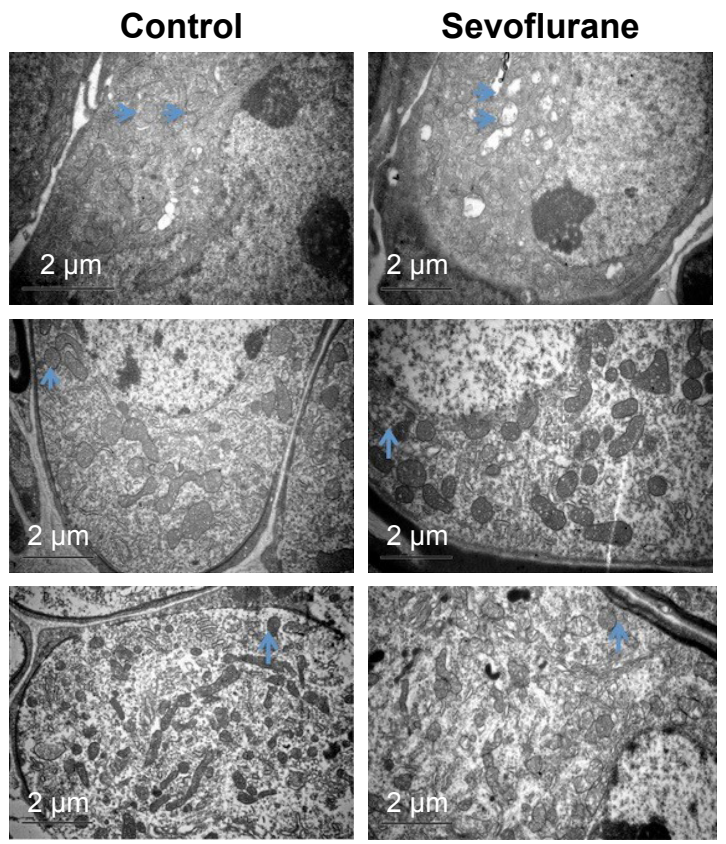

Neuron

Figure 4 Mitochondrial ultrastructure in cochlear hair cells and neurons evaluated by transmission electron microscopy on postnatal day (P) I, PI5, and P30.

Notes: On PI, swollen mitochondria (arrows) were more prominent in the sevoflurane group than in the control group. The swollen mitochondrial mass gradually decreased as the offspring mice became older $(\operatorname{Bar}=2.0 \mu \mathrm{m}$; magnification $\times 9700)$. 
A

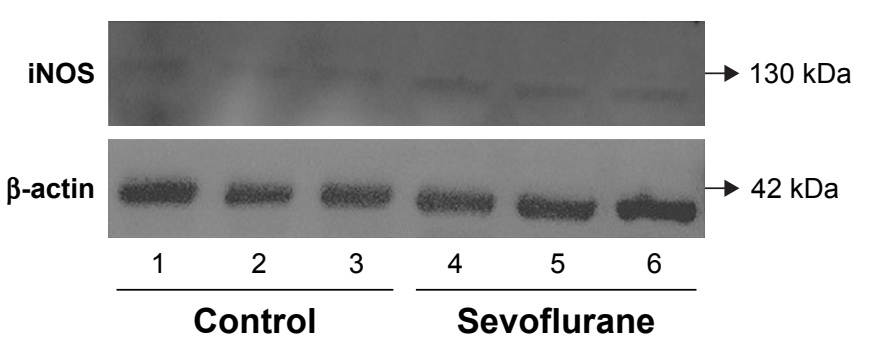

C

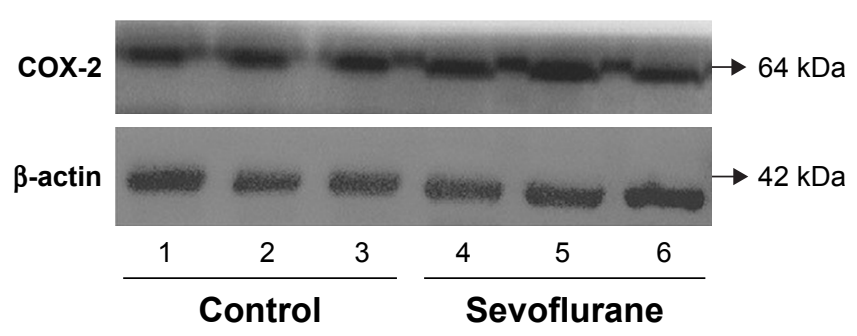

B

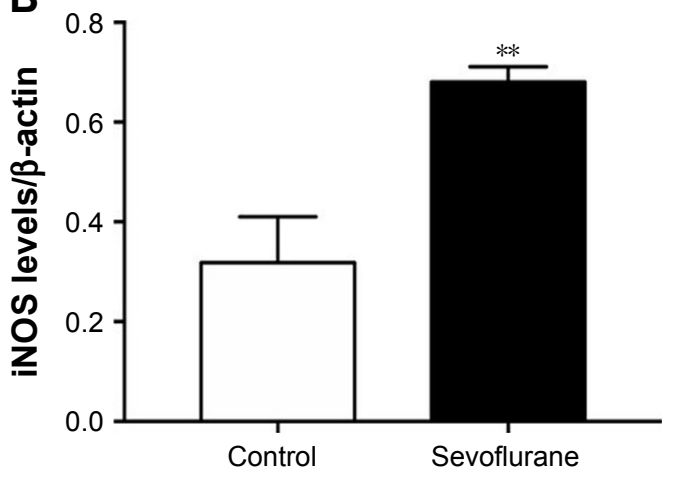

D

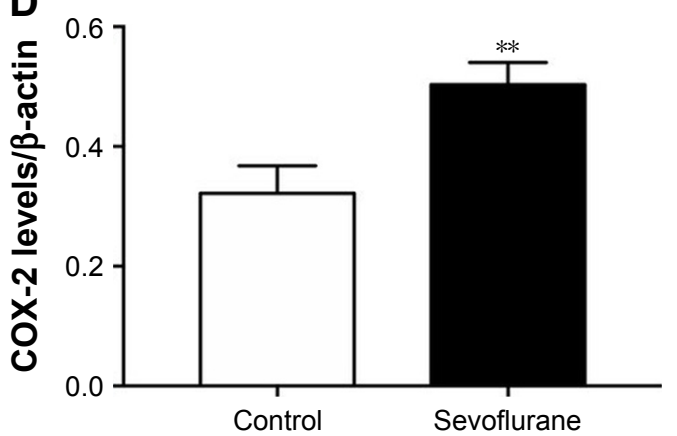

Figure 5 Anesthesia with $2.5 \%$ sevoflurane for 2 hours in pregnant mice on the 15 th day of gestation induced iNOS and COX-2 activation in the cochlear tissues of fetal mice. Notes: Representative Western blot images of iNOS and semiquantification of the Western blot (A and B). Representative Western blot images of COX-2 and semiquantification of the Western blot $(\mathbf{C}$ and $\mathbf{D})$. $* * P<0.00$ I.

Western blot testing showed that SEV anesthesia for 2 hours in pregnant mice at G15 induced activation of iNOS and COX-2 in fetal mice cochlear tissues. Semiquantification of the Western blot results revealed that both cochlear tissue iNOS levels (Figure 5A and B) and COX-2 (Figure 5C and D) were higher in SEV group.

\section{Discussion}

The current study demonstrates that SEV anesthesia administered to pregnant mice induces activation of caspase-3, iNOS, and COX-2 in the cochlear tissues of fetal mice. It also induces longer term adverse effects in offspring mice, including swollen mitochondria in cochlear hair cells and neurons and abnormal ABRs. Potential mechanism of SEV induced hearing impairment, as shown as Figure 6.

Several studies have confirmed that SEV anesthesia does not cause dramatic changes in blood gas values. ${ }^{21-23}$ Dong et al showed that 2 hours of $2.5 \% \mathrm{SEV}$ anesthesia could produce neurotoxic effects in the brain tissues of adult mice in the absence of alterations in blood pressure or blood gas values. ${ }^{23}$ In the current study, mean venous blood gas values

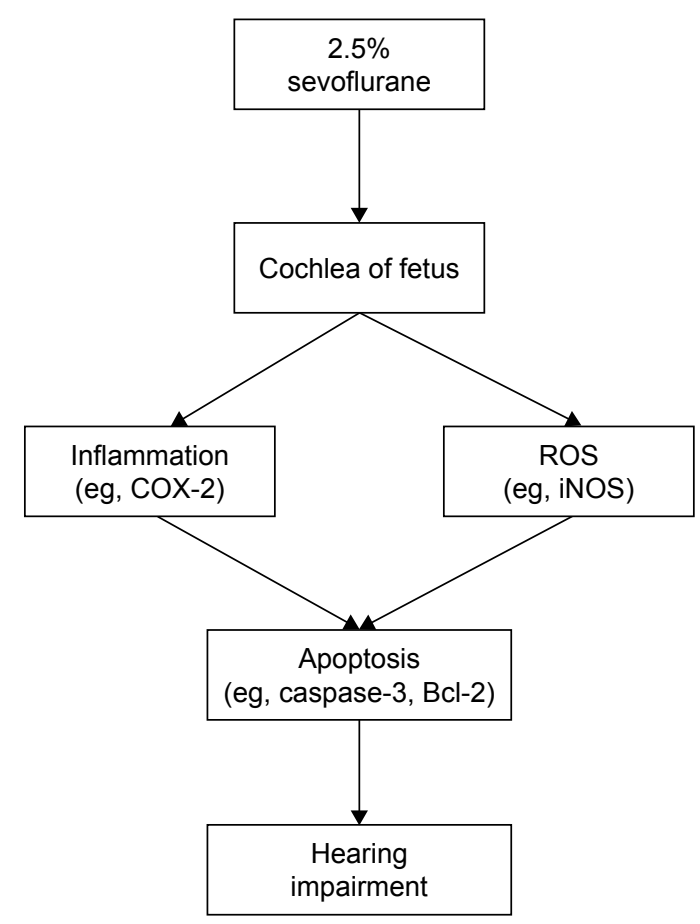

Figure 6 Potential mechanism of sevoflurane induced hearing impairment. Note: The inflammation and reactive oxygen species (ROS) caused by sevoflurane resulted in apoptosis in the cochlea of the fetus and hearing impairment in offspring. 
of the pregnant mice during SEV anesthesia did not differ significantly from those observed in control group mice.

$\mathrm{ABR}$ assessment is commonly used in both laboratory and clinical settings for diseases of the inner ear, cerebellopontine angle, and central auditory pathway. ${ }^{24} \mathrm{ABR}$ threshold measurements are also used to evaluate changes in hearing ability. ${ }^{2,19}$ Zheng et a $1^{18}$ previously reported that $2.5 \%$ SEV exposure in pregnant mice was associated with neurotoxic effects in the fetus, as well as neurobehavioral defects after birth. In the current study, our aim was to test whether this clinically relevant concentration has detrimental effects on the developing auditory system. We found that SEV exposure in pregnant mice did have detrimental auditory effects in the offspring. Specifically, elevated hearing thresholds were noted during ABR testing at different frequencies, which indicated the presence of hearing impairment in the offspring. Prolonged wave II peak latencies were observed, which suggest the presence of delayed neural transmission, and prolonged wave II to V interpeak latencies were noted, which suggest the presence of reduced myelin or impaired synaptic efficiency within the brainstem. We do not know whether SEV, or its metabolite compound A, induces the neurotoxicity. Further studies will include the studies to assess the effects of compound A on auditory system.

Different anesthetic agents may have different influences on ABR potentials. Alcohol has been reported to increase the latency and reduce the amplitude of ABR signals. ${ }^{25}$ Isoflurane has been shown to prolong the peak latencies of wave III and wave V, resulting in increased interpeak latencies. ${ }^{26-29}$ Ketamine has no effect on ABR thresholds. ${ }^{29}$ The combination of ketamine and xylazine is commonly used to immobilize animals during ABR testing. ${ }^{19}$ In the current study, we used this combination during ABR assessments, and the control mice exhibited normal ABR signals.

NMDA inhibition and GABA-receptor complex activation have been proposed as the underlying mechanisms of apoptotic neurodegeneration. ${ }^{30}$ Furthermore, otic placode cell death has been reported in mouse embryos exposed to alcohol. ${ }^{14}$ In the current study, SEV exposure in pregnant mice induced caspase-3 activation in fetal cochlear tissue, suggesting that SEV caused cell apoptosis in the developing auditory system. In the current study, we found that expression of Bcl-2 increased in fetal cochlear tissue immediately after SEV exposure. Similarly, Yuan et al found that Bcl-2 increased at early stage of apoptosis in human cartilage endplate-derived stem cells. ${ }^{31}$

Reactive oxygen species accumulation and mitochondrial dysfunction have been suggested as upstream mechanisms of the activation of caspase- 3 induced by isoflurane..$^{32,33}$ In the current study, we observed the ultrastructure of the cochlear tissue cells in the offspring mice. On P1, a large number of swollen mitochondria was observed in the cochlear hair cells and neurons in the offspring of mice exposed to SEV during their pregnancy, and the number of swollen mitochondria was still greater than in the control group at P15. Furthermore, we found that iNOS and COX-2 expression were increased in fetal cochlear tissue. These observations suggest that SEV exposure in pregnant mice caused oxidative stress and mitochondrial dysfunction in the cochlear tissues, which led to cell death.

\section{Limitations}

There were limitations in our study. First, we evaluated the activity of enzymes in only one location (cochlear tissues). SEV exposure in pregnant mice may also produce other changes in other parts of the auditory path. Second, we did not identify which cells in the cochlea contributed to the caspase-3 activation. Neuron apoptosis may be the most likely cause. Previous reports that isoflurane inhibits neurotransmitter release ${ }^{34}$ suggest that the neurotransmitter system is present in the cochlea of mammals and plays an important role in hearing. Third, we conducted anesthesia with $100 \% \mathrm{O}_{2}$ concentration. This may do not reflect the clinical situation and might interfere, through potential oxygen toxicity, with the assessment of anesthesia toxicity. However, in our control group, the fetal mice did not show substantial mitochondrial swelling. In addition, Zheng et a $1{ }^{18}$ used $100 \%$ oxygen concentration for pregnant mice in their study to assess anesthesia toxicity. Fourth, we only explored the effect of SEV on cochlea, and further studies are warranted to explore the effect of SEV on central auditory system.

\section{Conclusion}

SEV exposure in pregnant mice induced caspase-3 activation in the cochlea of fetal mice, as well as mitochondrial swelling in cochlear tissues and hearing impairment in the offspring after birth. The findings of our study implied that SEV might induce toxicity to the developing auditory system in fetus. Cautions should be taken when SEV is applied to pregnant women for nonobstetric surgery under general anesthesia. SEV-sulfobutylether- $\beta$-cyclodextrin (SBE $\beta C D$ ) complex, the improvement of SEV, is characterized by improved bioavailability and the blood-brain barrier permeability. ${ }^{35}$ Use of SEV-SBE $\beta C D$ complex may lead to a dose reduction and thus might abolish ototoxicity. Further studies are warranted to compare SEV and SEV-SBE $\beta C D$ in terms of ototoxicity. 


\section{Acknowledgment}

The research described in this report was supported by the National Natural Science Foundation of China (81300936, 81671045) and Shanghai Municipal Health Bureau (20154Y0144). The abstract was presented at Anesthesiologists Annual Meeting in 2017, Boston.

\section{Author contributions}

Xia Shen and Huiqian Yu designed the study. Yanan Xiao, Wen Li, and Kaizheng Chen conducted the study. Xia Shen and Huiqian Yu analyzed the data. Xia Shen and Huiqian Yu wrote the manuscript, and the other authors participated in the paper revisions. All Authors contributed toward data analysis, drafting and revising the paper and agree to be accountable for all aspects of the work.

\section{Disclosure}

The authors report no conflicts of interest in this work.

\section{References}

1. Baltes PB, Lindenberger U. Emergence of a powerful connection between sensory and cognitive functions across the adult life span: a new window to the study of cognitive aging? Psychol Aging. 1997; 12(1):12-21.

2. Kraus KS, Smitra S, Jimenez Z, et al. Noise trauma impairs neurogenesis in the rat hippocampus. Neuroscience. 2010;167(4):1216-1226.

3. Yu YF, Zhai F, Dai CF, Hu JJ. The relationship between age-related hearing loss and synaptic changes in the hippocampus of C57BL/6J mice. Exp Gerontol. 2011;46(9):716-722.

4. Lin FR, Yaffe K, Xia J, et al; Health ABC Study Group. Hearing loss and cognitive decline in older adults. JAMA Intern Med. 2013; 173(4):293-299.

5. Lewis N. Otitis media and linguistic incompetence. Arch Otolaryngol. 1976;102(7):387-390.

6. Teele DW, Klein JO, Rosner BA. Epidemiology of otitis media in children. Ann Otol Rhinol Laryngol Suppl. 1980;89(3 Pt 2):5-6.

7. Church MW, Overbeck GW. Prenatal cocaine exposure in the LongEvans rat. III. Developmental effects on the brainstem auditory-evoked potential. Neurotoxicol Teratol. 1990;12(4):345-351.

8. Church MW, Overbeck GW. Sensorineural hearing loss as evidenced by the auditory brainstem response following prenatal cocaine exposure in the Long-Evans rat. Teratology. 1991;43(6):561-570.

9. McCartney JS, Fried PK, Watkinson B. Central auditory processing in school-age children prenatally exposed to cigarette smoke. Neurotoxicol Teratol. 1994;16(3):269-276.

10. Olney JW, Wozniak DF, Jevtovic-Todorovic V, Farber NB, Bittigau P, Ikonomidou C. Glutamate and GABA receptor dysfunction in the fetal alcohol syndrome. Neurotox Res. 2002;4(4):315-325.

11. Streissguth AP, O’Malley K. Neuropsychiatric implications and longterm consequences of fetal alcohol spectrum disorders. Semin Clin Neuropsychiatry. 2000;5(3):177-190.

12. Strasnick B, Jacobson JT. Teratogenic hearing loss. J Am Acad Audiol. 1995;6(1):28-38.

13. Church MW, Kaltenbach JA. Hearing, speech, language, and vestibular disorders in the fetal alcohol syndrome: a literature review. Alcohol Clin Exp Res. 1997;21(3):495-512.

14. Kotch LE, Sulik KK. Patterns of ethanol-induced cell death in the developing nervous system of mice; neural fold states through the time of anterior neural tube closure. Int J Dev Neurosci. 1992;10(4):273-279.
15. Palanisamy A, Baxter MG, Keel PK, Xie Z, Crosby G, Culley DJ. Rats exposed to isoflurane in utero during early gestation are behaviorally abnormal as adults. Anesthesiology. 2011;114(3):521-528.

16. Reitman E, Flood P. Anaesthetic considerations for non-obstetric surgery during pregnancy. Br J Anaesth. 2011;107 (Suppl 1):i72-i78.

17. Wilder RT, Flick RP, Sprung J, et al. Early exposure to anaesthesia and learning disabilities in a population-based birth cohort. Anesthesiology. 2009;110(4):796-804.

18. Zheng H, Dong Y, Xu Z, et al. Sevoflurane anesthesia in pregnant mice induces neurotoxicity in fetal and offspring mice. Anesthesiology. 2013;118(3):516-526.

19. Sun S, Sun MZ, Zhang YP, et al. In vivo overexpression of X-linked inhibitor of apoptosis protein protects against neomycin induced hair cell loss in the apical turn of the cochlea during the ototoxic-sensitive period. Front Cell Neurosci. 2014;8:248.

20. Yu HQ, Lin Q, Wang YF, et al. Inhibition of H3K9 methyltransferases G9a/GLP prevents ototoxicity and ongoing hair cell death. Cell Death Dis. 2013;4:e506.

21. Shen X, Dong YL, Xu ZP, et al. Selective anesthesia-induced neuroinflammation in developing mouse brain and cognitive impairment. Anesthesiology. 2013;118(3):502-515.

22. Zhang MQ, Ji MH, Zhao QS, et al. Neurobehavioural abnormalities induced by repeated exposure of neonatal rats to sevoflurane can be aggravated by social isolation and enrichment deprivation initiated after exposure to the anaesthetic. Br J Anaesth. 2015;115(5):752-760.

23. Dong Y, Zhang G, Zhang B, et al. The common inhalational anesthetic sevoflurane induces apoptosis and increases beta-amyloid protein levels. Arch Neurol. 2009;66(5):620-631.

24. Ruth RA, Lambert PR. Auditory evoked potentials. Otolaryngol Clin North Am. 1991;24(2):349-370.

25. Smith ES, Riechelmann H. Cumulative lifelong alcohol consumption alters auditory brainstem potentials. Alcohol Clin Exp Res. 2004;28: 508-515.

26. Manninen PH, Lam AM, Nicholas JF. The effects of isoflurane and isoflurane-nitrous oxide anesthesia on brainstem auditory evoked potentials in humans. Anesth Analg. 1985;64(1):43-47.

27. Stronks HC, Aarts MC, Klis SF. Effects of isoflurane on auditoryevoked potentials in the cochlea and brainstem of guinea pigs. Hear Res. 2010;260(1-2):20-29.

28. Legatt AD. Mechanisms of intraoperative brainstem auditory evoked potential changes. J Clin Neurophysiol. 2002;19(5):396-408.

29. Cederholm JM, Froud KE, Wong AC, Ko M, Ryan AF, Housley GD. Differential actions of isoflurane and ketamine-based anaesthetics on cochlear function in the mouse. Hear Res. 2012;292(1-2):71-79.

30. Fredriksson A, Pontén E, Gordh T, Eriksson P. Neonatal exposure to a combination of N-methyl-D-aspartate and gamma-aminobutyric acid type A receptor anesthetic agents potentiates apoptotic neurodegeneration and persistent behavioral deficits. Anesthesiology. 2007;107(3): 427-436.

31. Yuan C, Pu LQ, He ZL, Wang J. BNIP3/Bcl/2-mediated apoptosis induced by cyclic tensile stretch in human cartilage endplate - derived stem cells. Exp Ther Med. 2018;15(1):235-241.

32. Zhang $\mathrm{Y}, \mathrm{Xu} \mathrm{Z}$, Wang $\mathrm{H}$, et al. Anesthetics isoflurane and desflurane differently affect mitochondrial function, learning, and memory. Ann Neurol. 2012;71(5):687-698.

33. Zhang Y, Dong Y, Wu X, et al. The mitochondrial pathway of anesthetic isoflurane-induced apoptosis. J Biol Chem. 2010;285(6): 4025-4037.

34. Herring BE, Xie Z, Marks J, Fox AP. Isoflurane inhibits the neurotransmitter release machinery. J Neurophysiol. 2009;102(2):1265-1273.

35. Shityakov S, Puskás I, Pápai K, et al. Sevoflurane-sulfobutyletherbeta-cyclodextrin complex: preparation, characterization, cellular toxicity, molecular modeling and blood-brain barrier transport studies. Molecules. 2015;20(6):10264-10279. 


\section{Publish your work in this journal}

Drug Design, Development and Therapy is an international, peerreviewed open-access journal that spans the spectrum of drug design and development through to clinical applications. Clinical outcomes, patient safety, and programs for the development and effective, safe, and sustained use of medicines are the features of the journal, which

has also been accepted for indexing on PubMed Central. The manuscript management system is completely online and includes a very quick and fair peer-review system, which is all easy to use. Visit http://www.dovepress.com/testimonials.php to read real quotes from published authors.

Submit your manuscript here: http://www.dovepress.com/drug-design-development-and-therapy-journal 